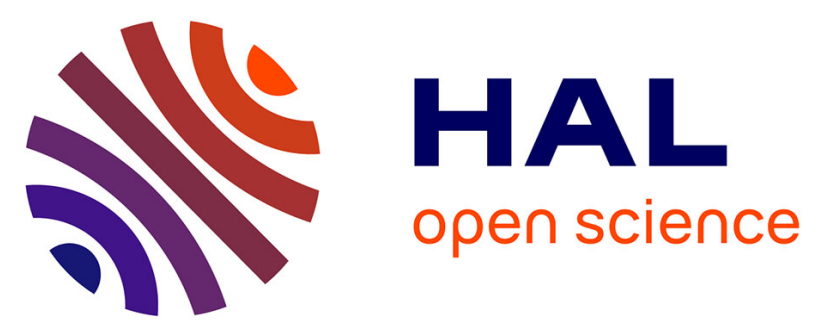

\title{
Surface immobilization of Mo6I8 octahedral cluster cores on functionalized amorphous carbon using a pyridine complexation strategy
}

Christian Godet, Soraya Ababou-Girard, Bruno Fabre, Yann Molard, A. Fadjie Djomkam, S. Députier, Maryline Guilloux-Viry, Stéphane Cordier

\section{To cite this version:}

Christian Godet, Soraya Ababou-Girard, Bruno Fabre, Yann Molard, A. Fadjie Djomkam, et al.. Surface immobilization of Mo6I8 octahedral cluster cores on functionalized amorphous carbon using a pyridine complexation strategy. Diamond and Related Materials, 2015, 55, pp.131-138. 10.1016/j.diamond.2015.03.011 . hal-01148517

\section{HAL Id: hal-01148517 https://hal.science/hal-01148517}

Submitted on 4 May 2015

HAL is a multi-disciplinary open access archive for the deposit and dissemination of scientific research documents, whether they are published or not. The documents may come from teaching and research institutions in France or abroad, or from public or private research centers.
L'archive ouverte pluridisciplinaire HAL, est destinée au dépôt et à la diffusion de documents scientifiques de niveau recherche, publiés ou non, émanant des établissements d'enseignement et de recherche français ou étrangers, des laboratoires publics ou privés. 


\section{Accepted Manuscript}

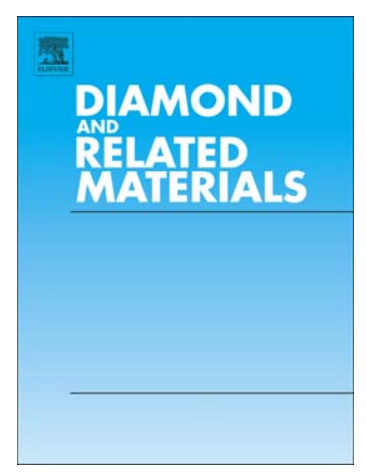

Surface immobilization of $\mathrm{Mo}_{6} \mathrm{I}_{8}$ octahedral cluster cores on functionalized amorphous carbon using a pyridine complexation strategy

C. Godet, S. Ababou-Girard, B. Fabre, Y. Molard, A.B. Fadjie-Djomkam, S. Députier, M. Guilloux-Viry, S. Cordier

PII:

S0925-9635(15)00049-7

DOI: doi: 10.1016/j.diamond.2015.03.011

Reference: DIAMAT 6385

To appear in: $\quad$ Diamond \& Related Materials

Received date: 22 January 2015

Revised date: $\quad 28$ February 2015

Accepted date: $\quad 9$ March 2015

Please cite this article as: C. Godet, S. Ababou-Girard, B. Fabre, Y. Molard, A.B. FadjieDjomkam, S. Députier, M. Guilloux-Viry, S. Cordier, Surface immobilization of $\mathrm{Mo}_{6} \mathrm{I}_{8}$ octahedral cluster cores on functionalized amorphous carbon using a pyridine complexation strategy, Diamond \& Related Materials (2015), doi: 10.1016/j.diamond.2015.03.011

This is a PDF file of an unedited manuscript that has been accepted for publication. As a service to our customers we are providing this early version of the manuscript. The manuscript will undergo copyediting, typesetting, and review of the resulting proof before it is published in its final form. Please note that during the production process errors may be discovered which could affect the content, and all legal disclaimers that apply to the journal pertain. 


\title{
Surface immobilization of $\mathbf{M o}_{6} \mathrm{I}_{8}$ octahedral cluster cores on functionalized amorphous carbon using a pyridine complexation strategy
}

\author{
C. Godet, ${ }^{\mathrm{a}} *$ S. Ababou-Girard, ${ }^{\mathrm{a}}$ B. Fabre, ${ }^{\mathrm{b}}$ Y. Molard, ${ }^{\mathrm{b}}$ \\ A.B. Fadjie-Djomkam, ${ }^{a}$ S. Députier, ${ }^{b}$ M. Guilloux-Viry, ${ }^{b}$ S. Cordier, ${ }^{\text {** }}$ \\ ${ }^{a}$ Institut de Physique de Rennes, CNRS UMR 6251, Université de Rennes 1, Campus de Beaulieu, \\ 35042 Rennes Cedex, France \\ ${ }^{b}$ Institut des Sciences Chimiques de Rennes, CNRS UMR 6226 CNRS, Université de Rennes 1, \\ Campus de Beaulieu, 35042 Rennes Cedex, France
}

Keywords : tetrahedral amorphous carbon, pulsed laser deposition (PLD), bonding configurations, surface characterization, electrical properties

${ }^{*}$ Corresponding authors. Tel: +33 223235706. E-mail: christian.godet@univ-rennes1.fr (C. Godet). Stephane.cordier@univ-rennes1.fr (S. Cordier) 


\section{ABSTRACT}

Tetrahedral amorphous carbon (a-C) films have been grown by pulsed laser deposition to investigate a liquid phase process for surface immobilization of electroactive $\left[\mathrm{Mo}_{6} \mathrm{I}_{8}^{\mathrm{i}}\right]^{4+}$ transition metal clusters cores using a complexation reaction with a pyridine-terminated alkyl monolayer covalently bonded to the a-C surface $\left(\mathrm{Py}^{\mathrm{S}}-\right.$ alkyl / a-C). These films are stable against thermallyassisted grafting of alkene molecules and the covalent $\mathrm{C}-\mathrm{C}$ interface provides a robust monolayer / a-C assembly. Octahedral $\left[\mathrm{Mo}_{6} \mathrm{I}_{8}^{\mathrm{i}}\right]^{4+}$ cluster cores with iodine inner ligands and labile triflate apical ligands $\left[\mathrm{Mo}_{6} \mathrm{I}_{8}^{\mathrm{i}}\left(\mathrm{CF}_{3} \mathrm{SO}_{3}\right)_{6}^{\mathrm{a}}\right]^{2-}$ have been immobilized through partial complexation in apical position by surface pyridine groups $\left(\mathrm{Py}^{\mathrm{S}}\right)$. Remaining $\mathrm{CF}_{3} \mathrm{SO}_{3}{ }^{-}$apical ligands of $\left[\mathrm{Mo}_{6} \mathrm{I}_{8}^{\mathrm{i}}\left(\mathrm{Py}^{\mathrm{S}}\right)^{\mathrm{a}}{ }_{\mathrm{y}}\right.$ $\left.\left(\mathrm{CF}_{3} \mathrm{SO}_{3}\right)^{\mathrm{a}}{ }_{6-\mathrm{y}}\right]$ cluster units were further substituted with bromopyridine (Py-Br) to obtain air stable surface with expected final composition $\left[\mathrm{Mo}_{6} \mathrm{I}_{8}^{\mathrm{i}}\left(\mathrm{Py}^{\mathrm{S}}\right)^{\mathrm{a}}{ }_{\mathrm{y}}(\mathrm{Py}-\mathrm{Br})_{6-\mathrm{y}}^{\mathrm{a}}\right]$. The yield of the different reaction steps is followed by X-ray photoelectron spectroscopy, providing cluster coverage $\Sigma_{\mathrm{Mo618}}=9 \times 10^{12} \mathrm{~cm}^{-2}$. Each $\left[\mathrm{Mo}_{6} \mathrm{I}_{8}\right]^{4+}$ cluster is bound to the carbon surface through multiple anchoring metal sites $\left(N_{\mathrm{PYR}}=3\right.$ or 4$)$, indicating that pyridine-terminated alkyl chains are flexible enough to accommodate four bonds. Electrical transport through $\mathrm{Hg} / / \mathrm{Mo}_{6} \mathrm{I}_{8}-\mathrm{Py}^{\mathrm{S}}-$ alkyl / a-C / p-Si(111) junctions show rectifying current-voltage characteristics but do not reveal any signature of cluster immobilization. 


\section{INTRODUCTION}

In addition to its early applications as hard protective coating and solid lubricant $[\mathbf{1}, \mathbf{2}]$, amorphous carbon $(\mathrm{a}-\mathrm{C})$ is receiving a growing interest as a chemically inert and biocompatible electronic material. Amorphous carbon films have been studied as injecting layers in organic light emitting diodes [3], as electrodes for analytical electrochemistry with a large overpotential in aqueous solvent [4-6] and as electronic bio-sensing substrates $[7,8]$.

For analytical and sensing applications, modification of carbon surfaces by molecular grafting has been strongly developed using various (photo-, electro-) chemical methods [5, 7-12]. In these fields, stability against temperature and electrical bias stress are important issues. Molecular systems with interesting redox properties have been immobilized on carbon to evaluate their potential interest for molecular memories and catalytic systems based on carbon-supported metals $[13,14]$. Several families of molecular systems with multiple oxidation levels have been considered, including porphyrins, ruthenium complexes, octahedral metal clusters ... [15-17].

In octahedral cluster chemistry, the basic building blocks are $\left[\left(\mathrm{M}_{6} \mathrm{~L}_{8}^{\mathrm{i}}\right) \mathrm{L}_{6}^{\mathrm{a}}\right]$ nanosized units $(\mathrm{M}$ $=\mathrm{Mo} ; \mathrm{L}=$ halogen, chalcogen; $\mathrm{L}^{\mathrm{a}}=$ apical ligand and $\mathrm{L}^{\mathrm{i}}=$ inner ligand) $[\mathbf{1 6}, \mathbf{1 7}, \mathbf{1 8}]$. The $\mathrm{M}_{6}$ cluster is face-capped by eight inner ligands to form rigid cluster cores characterized by covalent M-L ${ }^{i}$ bonds (Scheme 1) [19]. The cluster cores are ionically bound to apical ligands located in terminal position. The intrinsic physicochemical properties (optical, electronic and redox) of these octahedral transition metal clusters are strongly related to the number of electrons available for metal-metal bonds within the cluster [20]. These electrons are localized on a set of twelve metal-bonding molecular orbitals for the $\left[\left(\mathrm{M}_{6} \mathrm{~L}_{8}^{\mathrm{i}}\right) \mathrm{L}_{6}^{\mathrm{a}}\right]$ unit. Consequently, full occupation of these orbitals leads to a closed-shell configuration with twenty four valence electrons. These octahedral clusters can be further functionalized by substituting one or several labile apical 
ligand(s), e.g. trifluoromethanesulfonate (or triflate) groups $\left(\mathrm{CF}_{3} \mathrm{SO}_{3}{ }^{-}\right)$, with coordinating organic or inorganic moieties [21-25]. Indeed, metal atom cluster units are versatile building blocks that exhibit a well-defined organization and monodispersity particularly useful for nanoarchitectonics [26]. Beyond carrying specific luminescence, sensitization, catalytic and photo-catalytic properties [27-32], molecular assemblies and nanomaterials built up from $\mathrm{M}_{6}$ clusters could be involved in the material structuration by self-assembling of organic cationic frameworks in charge transfer salts thanks to their ability to form hydrogen bonding. Versatility of metal atom clusters can also be used for the functionalization of surfaces [33] including semiconducting electrodes.

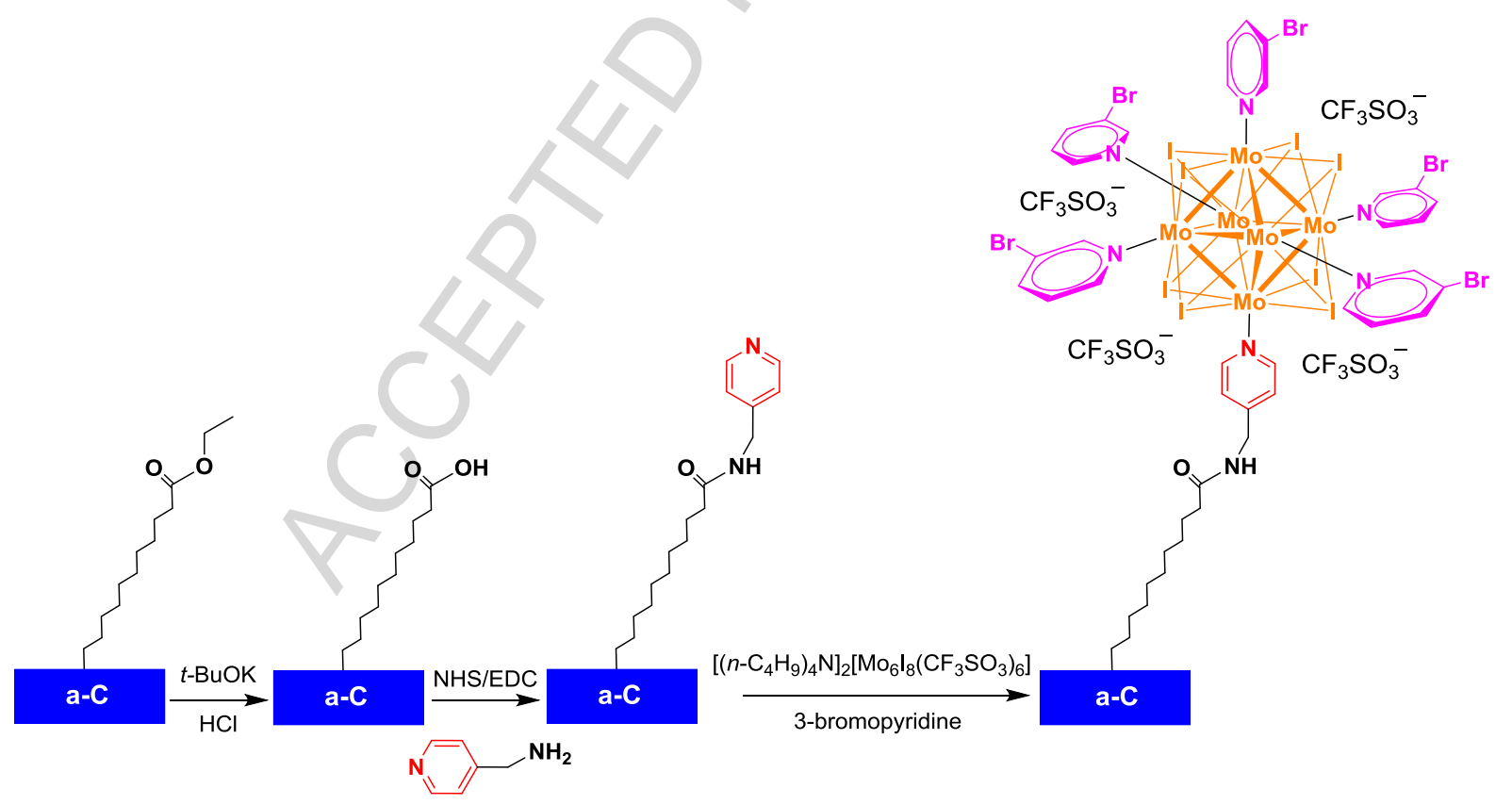

Scheme 1. Surface immobilization of a $\left[\mathrm{Mo}_{6} \mathrm{I}_{8}\right]^{4+}$ metallic cluster core on amorphous carbon through complexation with a pyridine-terminated alkyl monolayer. For clarity, a single anchoring site is shown, however complexation with more than one anchoring site is also possible. In the final reaction step (Scheme 2), the remaining apical sites are substituted with bromopyridine. 
I) $\left(\left(n-\mathrm{C}_{4} \mathrm{H}_{9}\right)_{4} \mathrm{~N}\right)_{2}\left[\mathrm{Mo}_{6} \mathrm{I}_{8}{ }^{\mathrm{i}} \mathrm{I}_{6}{ }_{6}^{\mathrm{a}}\right]+\mathrm{x} \mathrm{AgCF}_{3} \mathrm{SO}_{3} \rightarrow\left(\left(n-\mathrm{C}_{4} \mathrm{H}_{9}\right)_{4} \mathrm{~N}\right)_{2}\left[\mathrm{Mo}_{6} \mathrm{I}_{8}{ }^{\mathrm{i}} \mathrm{I}_{6-\mathrm{x}}^{\mathrm{a}}\left(\mathrm{CF}_{3} \mathrm{SO}_{3}\right)^{\mathrm{a}}{ }_{\mathrm{x}}\right]+\mathrm{x} \mathrm{AgI}$

II) $\quad\left(\left(n-\mathrm{C}_{4} \mathrm{H}_{9}\right)_{4} \mathrm{~N}\right)_{2}\left[\mathrm{Mo}_{6} \mathrm{I}_{8}^{\mathrm{i}} \mathrm{I}_{6-\mathrm{x}}^{\mathrm{a}}\left(\mathrm{CF}_{3} \mathrm{SO}_{3}\right)^{\mathrm{a}}{ }_{\mathrm{x}}\right]+\mathrm{y}\left(\mathrm{Py}^{\mathrm{S}}\right) \rightarrow$

$\left.\left(\mathrm{CF}_{3} \mathrm{SO}_{3}\right)_{\mathrm{y}-2}\left[\mathrm{Mo}_{6} \mathrm{I}_{8}^{\mathrm{i}} \mathrm{I}_{6-\mathrm{x}}^{\mathrm{a}}\left(\mathrm{Py}^{\mathrm{S}}\right)_{\mathrm{y}}^{\mathrm{a}}\left(\mathrm{CF}_{3} \mathrm{SO}_{3}\right)_{\mathrm{x}-\mathrm{y}}^{\mathrm{a}}\right]+2\left(n-\mathrm{C}_{4} \mathrm{H}_{9}\right)_{4} \mathrm{~N}\right) \mathrm{CF}_{3} \mathrm{SO}_{3}$

III) $\left(\mathrm{CF}_{3} \mathrm{SO}_{3}\right)_{\mathrm{y}-2}\left[\mathrm{Mo}_{6} \mathrm{I}_{8}^{\mathrm{i}} \mathrm{I}_{6-\mathrm{x}}^{\mathrm{a}}\left(\mathrm{Py}^{\mathrm{S}}\right)^{\mathrm{a}}{ }_{\mathrm{y}}\left(\mathrm{CF}_{3} \mathrm{SO}_{3}\right)_{\mathrm{x}-\mathrm{y}}^{\mathrm{a}}\right]+(\mathrm{x}-\mathrm{y}) \mathrm{Py}-\mathrm{Br} \rightarrow$

$$
\left(\mathrm{CF}_{3} \mathrm{SO}_{3}\right)_{\mathrm{x}-2}\left[\mathrm{Mo}_{6} \mathbf{I}_{8}^{\mathrm{i}} \mathbf{I}_{6-\mathrm{x}}^{\mathrm{a}}\left(\mathrm{Py}^{\mathrm{S}}\right)_{\mathrm{y}}^{\mathrm{a}}(\mathbf{P y}-\mathrm{Br})_{\mathrm{x}-\mathrm{y}}^{\mathrm{a}}\right]
$$

Scheme 2. Three-step reaction corresponding to the immobilization of $\left[\mathrm{Mo}_{6} \mathrm{I}_{8}\right]^{4+}$ metallic cluster cores on a-C surfaces through complexation with pyridine-terminated alkyl monolayers. Partial substitution $(x<6)$ is observed in step I. The surface pyridine anchoring sites $\left(y=N_{\mathrm{PYR}}\right)$ are denoted as $\left(\mathrm{Py}^{\mathrm{S}}\right)$ in steps II and III.

The immobilization of octahedral molybdenum-based cluster cores $\left[\mathrm{Mo}_{6} \mathrm{I}_{8}\right]^{4+}$ on crystalline silicon $\operatorname{Si}(111)$ substrates ( $n$-type and $p$-type) has been previously reported $[\mathbf{3 4 , 3 5 ]}$. It was shown that the reaction of $\left[\left(n-\mathrm{C}_{4} \mathrm{H}_{9}\right)_{4} \mathrm{~N}_{2}\left[\mathrm{Mo}_{6} \mathrm{I}_{8}\left(\mathrm{CF}_{3} \mathrm{SO}_{3}\right)_{6}\right]\right.$ with pyridine derivatives $(\mathrm{Py}-\mathrm{R})$ leads easily to the formation of $\left[\mathrm{Mo}_{6} \mathrm{I}_{8}(\mathrm{Py}-\mathrm{R})_{6}^{\mathrm{a}}\right]^{4+}$ species both in solution and on surfaces; triflates are substituted by pyridine groups which are known to form strong covalent and stable Mo-N bonds with $\mathrm{Mo}_{6}$ clusters. Electronic properties of $\mathrm{Mo}_{6} \mathrm{I}_{8}-$ Pyridine - alkyl - a-C system are likely to depend on surface coverage of $\left[\mathrm{Mo}_{6} \mathrm{I}_{8}\right]^{4+}$ cluster cores $\left(\Sigma_{\text {Mo6is }}\right)$ while the robustness of the immobilization is related with the anchoring configuration basically defined by the number $N_{\mathrm{PYR}}$ of surface pyridine $\left(\mathrm{Py}^{\mathrm{S}}\right)$ moieties attached to each cluster. 
This work aims at understanding the chemical reaction path of the $\left[\mathrm{Mo}_{6} \mathrm{I}_{8}\right]^{4+}$ cluster core complexation by a pyridine-functionalized surface in order to quantify the number of surface anchoring sites per $\left[\mathrm{Mo}_{6} \mathrm{I}_{8}\right]^{4+}$ cluster core. X-ray photoelectron spectroscopy (XPS) analysis of the immobilized cluster monolayer is performed to estimate the surface coverage and to determine the number, $N_{\mathrm{PYR}}$, of surface pyridine moieties attached to each cluster and the chemical nature of the (6- $\left.N_{\mathrm{PYR}}\right)$ remaining apical groups. Bromine from $\mathrm{Py}-\mathrm{Br}$ ligand serves as a local XPS probe in order to estimate the number of molybdenum atoms per cluster not involved in the immobilization and thus to indirectly determine the number of $\mathrm{Py}^{\mathrm{S}}$ involved in the attachment of $\mathrm{Mo}_{6}$ on the surface. However, in the case of Si substrates, it has been shown that quantitative XPS data analysis is hampered by the intense Si 2s plasmon losses $(168 \mathrm{eV}, 185 \mathrm{eV})$ overlapping both the S 2p (sulphur from triflate moieties), the I 4s (inner and apical ligands) and the $\mathrm{Br} 3 \mathrm{p}$ (bromine from the labelling bromopyridine groups) core level peaks [35]. Hence, the $\mathrm{Mo}_{6} \mathrm{I}_{8}$ - pyridine - alkyl - a-C system provides better opportunity for a quantitative XPS analysis of the above chemical elements. In addition, the very low surface roughness $(0.3-0.6 \mathrm{~nm})$ of amorphous carbon [36] is also interesting for quantitative XPS analysis of the cluster coverage.

Pulsed Laser Deposition (PLD) has been chosen to produce dense and smooth tetrahedral a-C films with a high $\mathrm{sp}^{3}$ hybridization; since this $\mathrm{sp}^{3}$ fraction does not exceed $60 \%$ in the few $\mathrm{nm}$ from the surface, the main reactive chemical groups are probably $\mathrm{C}-\mathrm{H}$ terminations and $\mathrm{C}=\mathrm{C}$ double bonds [37]. a-C films can be reproducibly grafted with alkene molecules with no previous surface preparation, using the same thermally assisted process as used with hydrogenated crystalline $\mathrm{Si}(111): \mathrm{H}$ surfaces [36], leading to the covalent immobilization of a dense alkyl monolayer (with ester or pyridine end-capping).

The coverage and the composition of the grafted molecular layers are estimated from quantitative XPS analysis at different steps of the grafting process. The oxidation state, derived 
from the binding energy of Mo core levels, is also compared to that of the precursor (polycrystalline powder). The number of surface anchoring sites is also deduced from XPS analysis to estimate the efficiency of the immobilization process. Electrical transport properties of metal-insulator-semiconductor (MIS) diodes obtained from functionalized a-C films were also investigated using a mercury drop as the soft electrical top contact to check possible changes in the electronic properties of a-C after the alkyl monolayer grafting and whether some signature of the monolayer of electroactive $\left[\mathrm{Mo}_{6} \mathrm{I}_{8}\right]^{4+}$ clusters can be detected after immobilization.

\section{Experimental}

The cluster immobilization strategy (Scheme 1 and 2) is based on a complexation reaction of the electrically neutral precursor $\left[\left(n-\mathrm{C}_{4} \mathrm{H}_{9}\right)_{4} \mathrm{~N}_{2}\left[\mathrm{Mo}_{6} \mathrm{I}_{8}^{\mathrm{i}} \mathrm{I}_{6-\mathrm{x}}^{\mathrm{a}}\left(\mathrm{CF}_{3} \mathrm{SO}_{3}\right)^{\mathrm{a}}{ }_{\mathrm{x}}\right]\right.$ in which a number $N_{\mathrm{PYR}}$ of the labile triflate groups in apical position are displaced by the surface pyridine groups to form $\mathrm{Mo-Py}^{\mathrm{S}}$ bonding. To obtain derivatized surfaces sufficiently stable for subsequent characterizations, in a final step III, the $\left(6-N_{\mathrm{PYR}}\right)$ remaining triflate groups $\left(\mathrm{CF}_{3} \mathrm{SO}_{3}\right)$ are displaced by reaction with a more stable complexation moiety. Bromopyridine has been chosen because $\mathrm{Br}$ atoms are useful as labelling moieties to improve the XPS analysis accuracy. Electrical neutrality of the cluster monolayer requires the presence of counter ions, e.g tetrabutylammonium $\mathrm{TBA}^{+}$ $\left(\left(n-\mathrm{C}_{4} \mathrm{H}_{9}\right)_{4} \mathrm{~N}^{+}\right)$(step I) or triflate $\mathrm{CF}_{3} \mathrm{SO}_{3}{ }^{-}$(step III). Owing to the octahedral geometry of the cluster and the steric hindrance of the pyridine - alkyl chains bonded to the semiconductor surface, all six Mo atoms cannot be simultaneously attached to surface pyridine groups. Scheme 1 shows the minimal anchoring configuration where each cluster is linked to the surface through a single pyridine $\left(\mathrm{Py}^{\mathrm{S}}\right)$ moiety. 


\subsection{Pulsed laser deposition of amorphous carbon}

Carbon films (30 $\mathrm{nm}$ thick) were grown at room-temperature by pulsed laser deposition using a $\mathrm{KrF}$ laser (Tuilaser Excistar E20, $\lambda=248 \mathrm{~nm}, 2 \mathrm{~Hz}, 40 \mathrm{~ns}$ pulse width) in a turbo-pumped high vacuum chamber (base pressure $\sim 10^{-4} \mathrm{~Pa}$ ). Crystalline silicon (c-Si(111), $p$-type) substrates were cleaned in ultrasonic bath (acetone, isopropanol, water) and dropped in $\mathrm{NH}_{4} \mathrm{~F}(40 \%)$ to remove their native oxide before a-C film growth. They were placed at $60 \mathrm{~mm}$ from the rotating glassy carbon target (Sigradur G, HTW). The deposited carbon thickness is $0.03 \mathrm{~nm} /$ pulse for a pulse energy of $150 \mathrm{~mJ}$ (fluence $7.3 \mathrm{~J} . \mathrm{cm}^{-2}$ ). Before deposition, the target was pre-cleaned for 5 minutes at $2 \mathrm{~Hz}$ with a shutter in front of the substrate. After deposition, nitrogen gas was introduced in the chamber and the carbon films were quickly transferred to the XPS setup or to the grafting setup under a dry nitrogen atmosphere.

\subsection{Preparation of the Molybdenum cluster-terminated carbon surfaces.}

Similar to our previous work with $\operatorname{Si}(111)$ :H surfaces [35], our strategy for anchoring $\left[\mathrm{Mo}_{6} \mathrm{I}_{8}\right]^{4+}$ cluster cores is based on the covalent derivatization of amorphous carbon surfaces by a complexing pyridine-terminated alkyl monolayer. Linear $\omega$-functionalized alkenes are used to obtain densely packed monolayers with a robust covalent bonding to the a-C substrate [38]. The first part of this thermally-induced grafting process includes successive surface reactions [39]: (i) covalent grafting of C10 linear alkenes, $\omega$-functionalized with ester moieties, (ii) conversion of terminal ester to reactive acid functionalities, (iii) amidation reaction with the amino-substituted pyridine. Briefly, ethyl undecylenate $\mathrm{CH}_{2}=\mathrm{CH}\left(\mathrm{CH}_{2}\right)_{8}-\mathrm{COOC}_{2} \mathrm{H}_{5}$ (Aldrich, 97\%) was passed through a neutral, activated alumina column to remove residual water and peroxides, before liquid-phase reaction at $160{ }^{\circ} \mathrm{C}$ for at least 2 hours. Using a protected ester (rather than an acid) functionality offers the advantage of limiting the possible reactivity of acid functions with the 
carbon surface. The terminal ester groups were further converted to acidic groups using dimethylformamide $(\mathrm{DMF})+0.25 \mathrm{M}$ potassium tert-butoxyde $(t-\mathrm{BuOK})$ for $10 \mathrm{~min}$, followed by $\mathrm{HCl} 1 \mathrm{M}$ [40]. The acid-terminated surface was rinsed with ultrapure water and activated with $N$ hydroxysuccinimide (NHS) (Acros, 98+\%) by immersion in a freshly prepared mixture of 1-(3dimethylaminopropyl)-3-ethylcarbodiimide (EDC) (Acros, 98+\%) and NHS in DMF. The covalent attachment of the functional units was performed by immersing the NHS-activated molecular layer / a-C film in a deaerated acetonitrile solution containing $0.1 \mathrm{M}$ of 4aminomethylpyridine (Aldrich, 98\%) at room temperature for 3.5 hours.

The cluster chemistry includes three major preparation steps, as summarized in Scheme 2.

Step I: the reaction of $\left[\left(n-\mathrm{C}_{4} \mathrm{H}_{9}\right)_{4} \mathrm{~N}_{2}\left[\mathrm{Mo}_{6} \mathrm{I}_{8}^{\mathrm{i}} \mathrm{I}_{6}^{\mathrm{a}}\right]\right.$ and $\mathrm{AgCF}_{3} \mathrm{SO}_{3}$ in refluxing THF is performed to remove and replace apical iodides by triflate $\left(\mathrm{CF}_{3} \mathrm{SO}_{3}{ }^{-}\right)$anions in apical positions $[23,41]$; the $\left[\left(n-\mathrm{C}_{4} \mathrm{H}_{9}\right)_{4} \mathrm{~N}\right]_{2}\left[\mathrm{Mo}_{6} \mathrm{I}_{8}\left(\mathrm{CF}_{3} \mathrm{SO}_{3}\right)_{6}\right]$ formula is expected for a complete reaction, where electrical neutrality is provided by two TBA ${ }^{+}$counter cations. However previous XPS characterizations of the precursor (crystallized by diffusion of ether in dry dichloromethane) [35] indicate incomplete replacement of apical iodine atoms $\left(\mathrm{I}^{\mathrm{a}}\right)$ by triflate groups, leading to the precursor formula $[(n$ $\left.\left.\mathrm{C}_{4} \mathrm{H}_{9}\right)_{4} \mathrm{~N}\right]_{2}\left[\mathrm{Mo}_{6} \mathrm{I}_{8} \mathrm{I}_{6-x}^{\mathrm{a}}\left(\mathrm{CF}_{3} \mathrm{SO}_{3}\right)_{\mathrm{x}}^{\mathrm{a}}\right](x<6)$ instead of $\left[\left(n-\mathrm{C}_{4} \mathrm{H}_{9}\right)_{4} \mathrm{~N}\right]_{2}\left[\mathrm{Mo}_{6} \mathrm{I}_{8}^{\mathrm{i}}\left(\mathrm{CF}_{3} \mathrm{SO}_{3}\right)_{6}^{\mathrm{a}}\right]$.

Step II: the $\left[\mathrm{Mo}_{6} \mathrm{I}_{8}\right]^{4+}$ cluster core is anchored on the pyridine-terminated a-C surface by immersing the modified a-C film overnight in a distilled dichloromethane solution (15 $\mathrm{mL})$ containing $8 \times 10^{-3} \mathrm{M}\left[\left(n-\mathrm{C}_{4} \mathrm{H}_{9}\right)_{4} \mathrm{~N}\right]_{2}\left[\mathrm{Mo}_{6} \mathrm{I}_{8}^{\mathrm{i}} \mathrm{I}_{6-\mathrm{x}}^{\mathrm{a}}\left(\mathrm{CF}_{3} \mathrm{SO}_{3}\right)_{\mathrm{x}}^{\mathrm{a}}\right]$ at $40^{\circ} \mathrm{C}$; the replacement of some labile triflate groups by the complexation reaction with surface pyridine groups $\left(\mathrm{Py}^{\mathrm{S}}\right)$, leads to a $\left(\mathrm{CF}_{3} \mathrm{SO}_{3}\right)_{\mathrm{y}-2}\left[\mathrm{Mo}_{6} \mathrm{I}_{8}^{\mathrm{i}} \mathrm{I}_{6-\mathrm{x}}^{\mathrm{a}}\left(\mathrm{Py}^{\mathrm{S}}\right)_{\mathrm{y}}^{\mathrm{a}}\left(\mathrm{CF}_{3} \mathrm{SO}_{3}\right)_{\mathrm{x}-\mathrm{y}}^{\mathrm{a}}\right]$ composition for the electrically neutral immobilized cluster, with $y=N_{\mathrm{PYR}}<x$. At this step II, the number of triflate counter anions, $y$-2, depends on the number of anchoring sites, $y$. 
Step III: to obtain derivatized surfaces sufficiently stable for subsequent characterization, the triflate anions remaining in apical position of the cluster after the immobilization step were substituted by 3-bromopyridine ( $\mathrm{Py}-\mathrm{Br}$ ) by dipping the modified surface in neat 3-bromopyridine (99\%, from Aldrich) for 30-40 min. Assuming that all apical triflates have been substituted and that electrically neutrality is provided by triflate counter anions, the expected final composition is $\left(\mathrm{CF}_{3} \mathrm{SO}_{3}\right)_{\mathrm{x}-2}\left[\mathrm{Mo}_{6} \mathrm{I}_{8}{ }^{\mathrm{i}}{ }^{\mathrm{a}}{ }_{6-\mathrm{x}}\left(\mathrm{Py}^{\mathrm{S}}\right)_{\mathrm{y}}^{\mathrm{a}}(\mathrm{Py}-\mathrm{Br})^{\mathrm{a}-\mathrm{y}}\right]$. After this step III, in order to remove physisorbed metallic aggregates, a thorough rinsing of the $\mathrm{Mo}_{6}$ cluster-modified surface with HPLC grade $\mathrm{CH}_{2} \mathrm{Cl}_{2}$ (previously distilled over $\mathrm{P}_{2} \mathrm{O}_{5}$ ) was performed [35].

\subsection{XPS analysis.}

After exposure to ambient atmosphere for a few minutes, the grafted carbon surfaces were introduced in the UHV chamber and kept at $1 \times 10^{-9}$ mbar for several hours before XPS analysis. XPS measurements were performed with $\mathrm{Mg} K \alpha(h v=1254 \mathrm{eV}) \mathrm{X}$-ray source, at an emission angle $\alpha$, using a VSW HA100 photoelectron spectrometer with a hemispherical photoelectron analyzer, at $22 \mathrm{eV}$ pass energy, providing an experimental resolution of $1.0 \mathrm{eV}$. Spectral analysis included a Shirley background subtraction and peak separation using mixed Gaussian-Lorentzian functions. Peak area ratios quoted in this work have been corrected for the photoemission cross section of each chemical element. Additional measurements were performed using a monochromatized Al $K \alpha(h v=1486.6 \mathrm{eV}) \mathrm{X}$-ray source to obtain a better peak separation for specific core levels.

In addition to the XPS analysis of metal (Mo) and inner ligands (I) to obtain their oxidation state, determination of the nature and number of ligands of the immobilized cluster $\left[\mathrm{Mo}_{6} \mathrm{I}_{8}^{\mathrm{i}} \mathrm{I}_{6-}{ }_{6}\right.$ $\left.{ }_{x}\left(\mathrm{Py}^{\mathrm{S}}\right)_{\mathrm{y}}^{\mathrm{a}}(\mathrm{Py}-\mathrm{Br})_{\mathrm{x}-\mathrm{y}}^{\mathrm{a}}\right]$ requires an accurate value of the bromine relative intensity. Once $x$ has been 
determined using some iodine core level, the $\mathrm{Br} 3 \mathrm{p}$ or $\mathrm{Br} 3 \mathrm{~d}$ core levels provide $x-y$, and hence the number of anchoring sites $y=N_{\mathrm{PYR}}$.

Molybdenum Mo 3d (rather than Mo 3p) and sulphur S 2p (rather than S 2s) photoelectron emission lines were chosen for their larger photoemission cross section; in contrast, the iodine I $4 d$ (rather than I 3d) line was used to avoid corrections for the dependence of the analyser sensitivity at small photoelectron kinetic energies. The bromine $\mathrm{Br} 3 \mathrm{~d}$ intensity can be compared with the stronger $\mathrm{Br} 3 \mathrm{p}$, although the latter are partially overlapped by the stronger I $4 \mathrm{~s}$ band.

The $\left[\mathrm{Mo}_{6} \mathrm{I}_{8}\right]^{4+}$ cluster core coverage, $\Sigma_{\text {Mo6I8 }}\left(\mathrm{cm}^{-2}\right)$, was derived from the Mo $3 \mathrm{~d}$ intensity through a normalization to the $\mathrm{C} 1 \mathrm{~s}$ intensity of a clean HOPG (highly oriented pyrolytic graphite, Neyco) substrate. Assuming that self-attenuation of the Mo signal by the cluster itself can be neglected, the density $\Sigma_{\mathrm{Mo6I}}$ of $\left[\mathrm{Mo}_{6} \mathrm{I}_{8}\right]^{4+}$ cluster cores $(m=6$ Mo atoms) per unit surface:

$$
\Sigma=\frac{1}{m} \frac{A_{M o}}{A_{H O P G}} \frac{\lambda_{C l s}^{H O P G}}{5.62} N_{H O P G}=6.01 \times 10^{14} \frac{A_{M o}}{A_{H O P G}}
$$

is derived from the measured peak areas $A_{\mathrm{Mo}}$ and $A_{\mathrm{HOPG}}\left(\mathrm{eV} \times\right.$ counts.s $\left.^{-1}\right)$, taking into account their

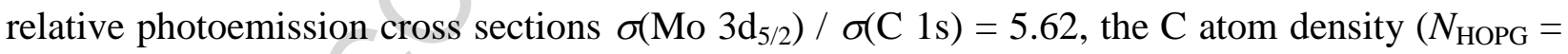
$11.4 \times 10^{22}$ at. $\mathrm{cm}^{-3}$ ) and the inelastic mean free path, $\lambda_{C l s}^{H O P G}=1.78 \mathrm{~nm}$, of $\mathrm{C} 1 \mathrm{~s}$ photoelectrons (with $970 \mathrm{eV}$ kinetic energy) in graphite [42]. A similar relationship applies for the coverage $(\Sigma$ PYR ) of the pyridine-functionalized a-C surface, using the $\mathrm{N} 1 \mathrm{~s}$ signal with $\sigma(\mathrm{N} 1 \mathrm{~s}) / \sigma(\mathrm{C} 1 \mathrm{~s})=$ 1.80 , and $m=2$ (pyridine and amide functions) if self-attenuation is neglected.

\subsection{Electrical Transport Measurements.}

Electrical transport measurements were performed on $\mathrm{Hg} / / \mathrm{Mo}_{6} \mathrm{I}_{8} /$ pyridine - alkyl / a-C / pSi junctions, using a mercury drop as a top electrode because its large surface tension $\left(480 \mathrm{~mJ} \mathrm{~m}^{-}\right.$ 
$\left.{ }^{2}\right)$ limits the occurrence of mercury diffusion through pinholes in the molecular layer. Current $(I)$ - voltage $(V)$ characteristics were obtained at room temperature using a Keithley 6487 picoammeter and a home-made setup with hanging $\mathrm{Hg}$ drop and a micromanipulator to adjust the contact area at $\sim 0.3 \mathrm{~mm}^{2}$. A fresh $\mathrm{Hg}$ drop $(99.999 \%$, Fluka) was used for each measurement, at several locations on the sample surface. An ohmic contact was made on the scratched rear side of the $p$-type Si substrate (resistivity 1-5 $\Omega . \mathrm{cm}$ ) by applying a silver paste electrode. In this work, the direct current transport characteristics were measured in a glove box with a humidity level of $22-25 \%$ of the water saturation pressure, after XPS measurements (under UHV) and a brief exposure to the ambient.

\section{Results}

\subsection{Amorphous carbon}

The a-C film thickness, $d_{a-C}=30 \mathrm{~nm}$, and optical properties were determined from spectroscopic ellipsometry. The refractive index $n(2 \mathrm{eV})=2.63$ is characteristic of a high density material [43], as confirmed by previous X-ray reflectivity measurements $\left(\rho=2.84 \mathrm{~g} . c m^{-3}\right)$ [37] and bulk plasmon energy $\left(E_{\mathrm{P}}=29.5 \pm 0.2 \mathrm{eV}\right)$ given by photoelectron energy loss spectroscopy; the surface hybridization of the as-grown a-C film $\left(\mathrm{sp}^{3} / \mathrm{sp}^{2}+\mathrm{sp}^{3}\right)$ was found to be $0.5-0.6$ from XPS measurements using a monochromatic X-ray source [37, 44].

Under optimized PLD conditions including the pre-cleaning of the target, amorphous carbon films suitable for monolayer grafting experiments are obtained, with a very smooth surface (rootmean-square roughness $\sim 0.3 \mathrm{~nm}$ ) as shown by Atomic Force Microscopy (AFM).

\subsection{Pyridine-functionalized $a-C$}


The XPS survey spectrum of the pyridine-modified carbon surface reveals characteristic peaks from the carbon substrate itself and from the $\mathrm{C} 1 \mathrm{~s}, \mathrm{O} 1 \mathrm{~s}$ and $\mathrm{N} 1 \mathrm{~s}$ core levels of the attached organic molecule (Fig. 1a). The shape and the intensity of these spectra as well as their relative positions in energy are consistent with the monolayer composition, with some additional $\mathrm{O} 1 \mathrm{~s}$ contribution due to some adventitious adsorbed oxygen or water molecules.

The $\mathrm{N} 1 \mathrm{~s}$ core level is characterized by a main peak at $400.4 \mathrm{eV}$ corresponding to the pyridine $\left(\mathrm{C}_{5} \mathrm{H}_{4} \underline{\mathrm{N}}\right)$ component and a shoulder at $399.2 \mathrm{eV}$ attributed to the amide $(\underline{\mathrm{N}}-\mathrm{C}=\mathrm{O})$ environment (not shown). The pyridine surface coverage is estimated at $\Sigma_{\mathrm{PYR}}=2.9 \times 10^{13} \mathrm{~cm}^{-2}$.

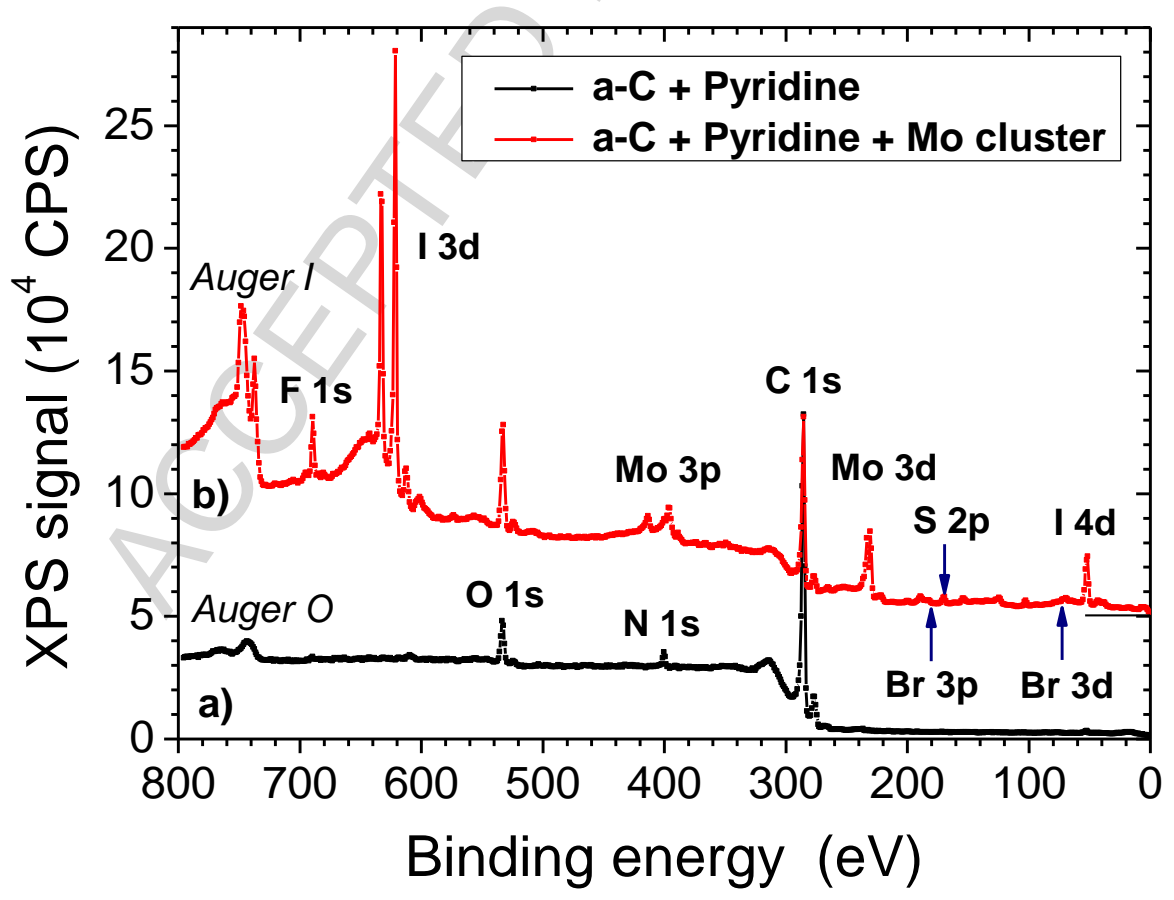

Fig. 1. XPS survey spectra $\left(\alpha=0^{\circ}\right)$ before (a) and after (b) immobilization of $\left[\mathrm{Mo}_{6} \mathrm{I}_{8}\right]^{4+}$ cluster cores on a pyridine-functionalized a-C surface (step II) followed by the complexation with bromopyridine (step III). 


\subsection{Mo $_{6} I_{8}$ - Pyridine - alkyl-a-C assembly}

After attachment of molybdenum clusters and treatment with 3-bromopyridine, as expected the survey spectrum (Fig. 1b) shows the presence of iodine and molybdenum atoms characterized by their respective $\mathrm{d}$ levels (I $3 \mathrm{~d}_{3 / 2}$, I $3 \mathrm{~d}_{5 / 2}$, Mo $3 \mathrm{~d}_{3 / 2}$, Mo $3 \mathrm{~d}_{5 / 2}$ and $\mathrm{I} 4 \mathrm{~d}_{5 / 2}$ at 632.5, 621.1, 232.8, 229.6 and $51.0 \mathrm{eV}$ respectively) and $3 p$ components (Mo 3p $3 / 2$ at $395.4 \mathrm{eV}$ ).

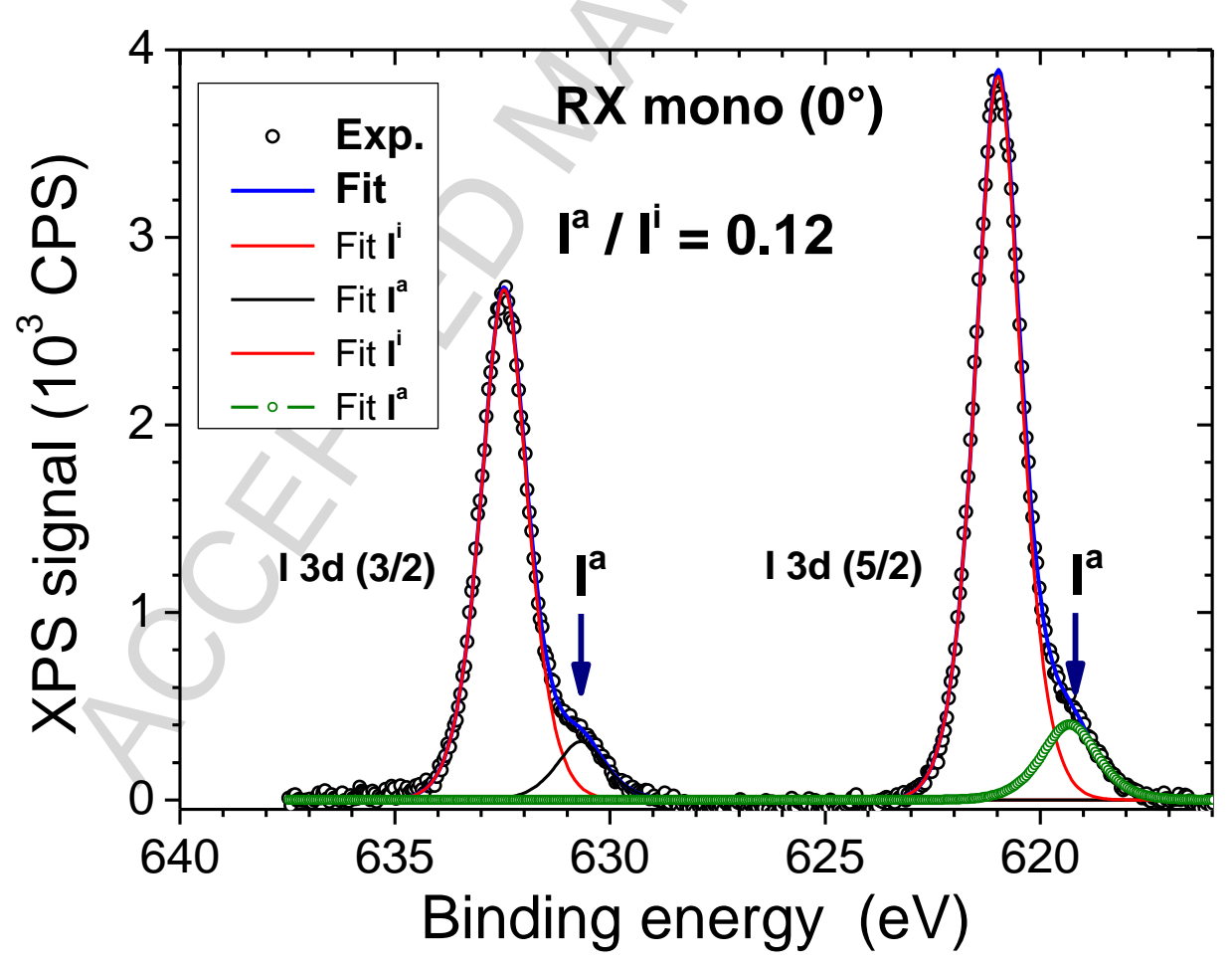

Fig. 2. XPS data ( $\alpha=0^{\circ}$, monochromatized X-ray source) showing the (I $\left.3 d_{3 / 2}, I 3 d_{5 / 2}\right)$ core level after $\left[\mathrm{Mo}_{6} \mathrm{I}_{8}\right]^{4+}$ cluster immobilization. Some unreacted apical ligands are observed at smaller binding energy than the inner iodine ligands with an intensity ratio $\left(\mathrm{I}^{\mathrm{a}} / \mathrm{I}^{\mathrm{i}}\right)=0.12$. 
Figure 2 shows the $\left(\mathrm{I}_{3 / 2}, \mathrm{I} 3 \mathrm{~d}_{5 / 2}\right)$ core level with the expected spin orbit splitting of 11.5 $\mathrm{eV}$. The main component corresponds to the eight inner iodine ligands, while a weaker component attributed to some apical ligands $\left(\mathrm{I}^{\mathrm{a}}\right)$, unreacted at step $\mathrm{I}$, is observed at smaller binding energy ( $\Delta E \approx 1.75 \mathrm{eV}$ ). Monochromatized X-ray source data were used to avoid baseline correction problems in the fitting of $\mathrm{I}^{\mathrm{i}}$ and $\mathrm{I}^{\mathrm{a}}$ components; the area ratio $\left(\mathrm{I}^{\mathrm{a}} / \mathrm{I}^{\mathrm{i}}\right)=0.12$ corresponds to an average of $0.96 \pm 0.1$ apical iodine per cluster. Qualitatively similar results are observed with the (I $\left.4 d_{3 / 2}, I 4 d_{5 / 2}\right)$ core level (not shown). Hence, only clusters with one apical iodine ligand were immobilized on a-C surface, which confirms previous results [35].

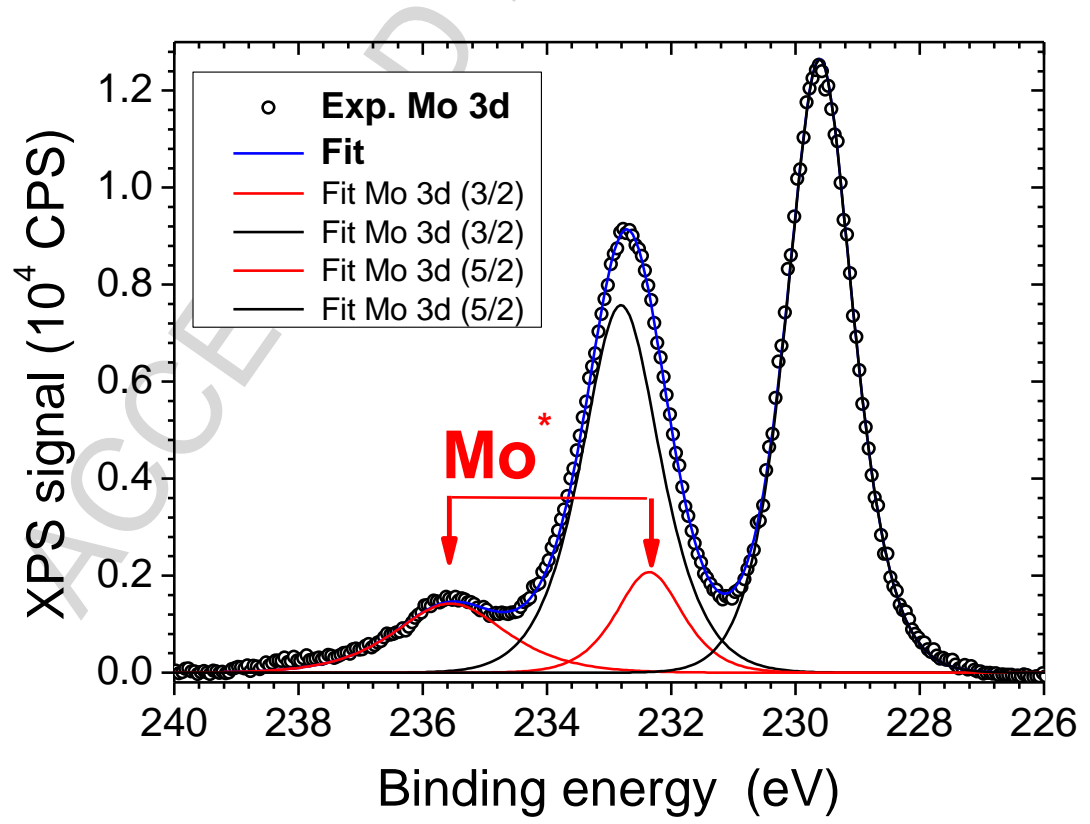

Fig. 3. XPS data $\left(\alpha=45^{\circ}\right)$ after $\left[\mathrm{Mo}_{6} \mathrm{I}_{8}\right]^{4+}$ cluster immobilization showing the Mo $3 \mathrm{~d}$ core level. Besides the strong (Mo $3 \mathrm{~d}_{3 / 2}$, Mo $3 \mathrm{~d}_{5 / 2}$ ) doublet, a smaller component Mo* (doublet with red arrows) is observed at larger binding energy $(\Delta E=2.74 \mathrm{eV})$. 
In Figure 3, the strong (Mo $3 \mathrm{~d}_{3 / 2}$, Mo $3 \mathrm{~d}_{5 / 2}$ ) doublet is observed with the expected $3.2 \mathrm{eV}$ spin orbit splitting. The positions of the main Mo $3 \mathrm{~d}_{5 / 2}$ and $3 \mathrm{~d}_{3 / 2}$ peaks are identical to that observed for the starting product $\left[\left(n-\mathrm{C}_{4} \mathrm{H}_{9}\right)_{4} \mathrm{~N}\right)_{2} \mathrm{Mo}_{6} \mathrm{I}_{14}$ and are perfectly consistent with a Mo ${ }^{\mathrm{II}}$ oxidation state. In addition, a smaller component (indicated as Mo*, red arrows) is observed at larger binding energy $(\Delta E \approx 2.75 \mathrm{eV})$ with an intensity ratio $\left(\mathrm{Mo}^{*} / \mathrm{Mo}^{\mathrm{II}}\right)=0.23 \pm 0.05$. Similarly, the broad Mo 3p level shows a peak tailing towards higher binding energies; as a consequence of the overlap between the N 1s and Mo 3p core levels (Fig. 4), the fitted ratio (N1s / Mo 3p) $=1.7$ is likely overestimated.

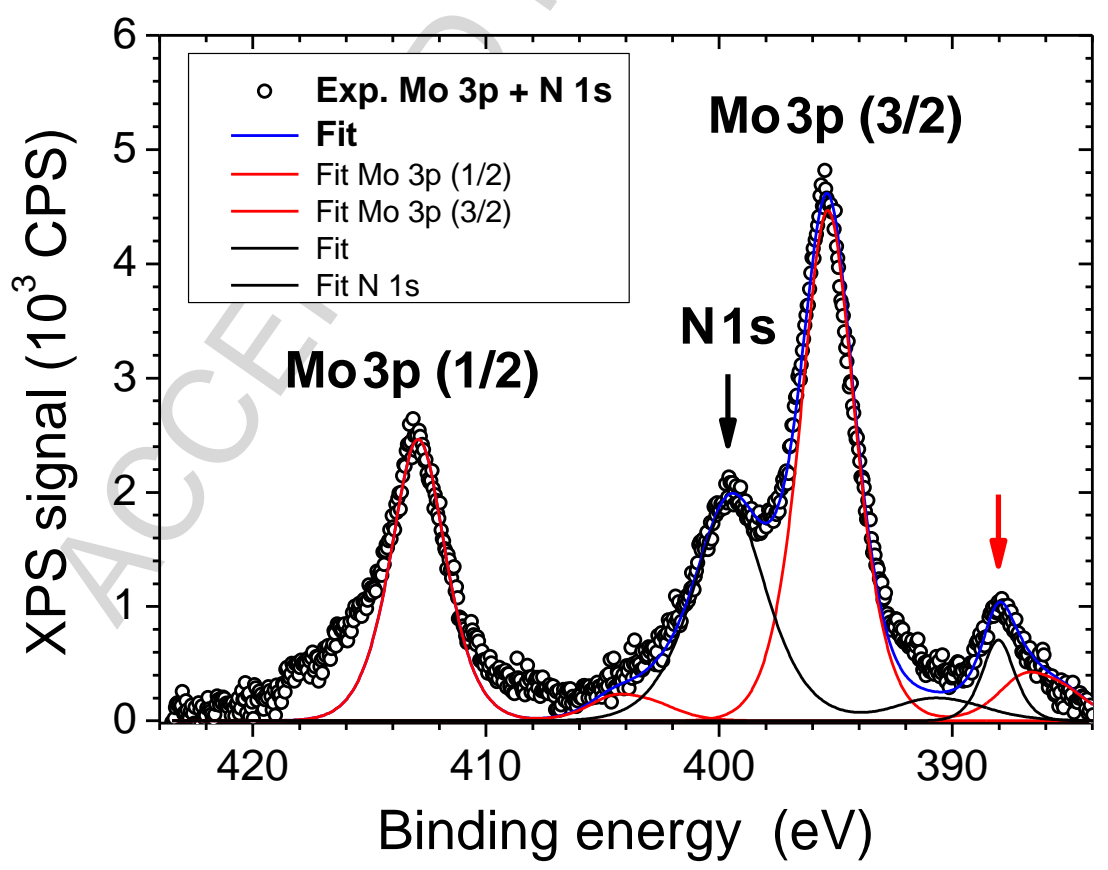

Fig. 4. XPS data $\left(\alpha=45^{\circ}\right)$ after $\left[\mathrm{Mo}_{6} \mathrm{I}_{8}\right]^{4+}$ cluster core immobilization showing the (Mo $3 \mathrm{p}_{1 / 2}$, Mo $3 p_{3 / 2}$ ) doublet and the $\mathrm{N} 1$ s core level. A broad tail is visible on the Mo $3 p_{1 / 2}$ peak at larger binding energies. The red arrow denotes a source satellite (absent with monochromatized X-ray source). 
The ratio between the total Mo $3 \mathrm{~d}_{5 / 2}$ area and the main $\mathrm{I}^{\mathrm{i}} 4 \mathrm{~d}$ peak area is estimated at $0.77 \pm 0.05$ which is close to the expected value for a $\left[\mathrm{Mo}_{6} \mathrm{I}_{8}\right]^{4+}$ cluster core $(0.75)$. However, the ratio between the $\mathrm{Mo}^{\mathrm{II}}$ (main peak) area and the $\mathrm{I}^{\mathrm{i}} 4 \mathrm{~d}$ peak area is estimated at $0.66 \pm 0.05$, indicating that the $\mathrm{Mo}^{*}$ component must be included in the cluster composition. The cluster coverage, $\Sigma=9.2 \times 10^{12} \mathrm{~cm}^{-2}$, deduced from the Mo 3d intensity using Equation 1, is consistent with a monolayer of bound $\left[\mathrm{Mo}_{6} \mathrm{I}_{8}\right]^{4+}$ cluster cores.

Besides the Mo 3d, the Br 3d core level clearly shows two components with different binding energies, in contrast with the iodine core atom and the counter anion elements ( $\mathrm{S}$ and $\mathrm{F}$ ).

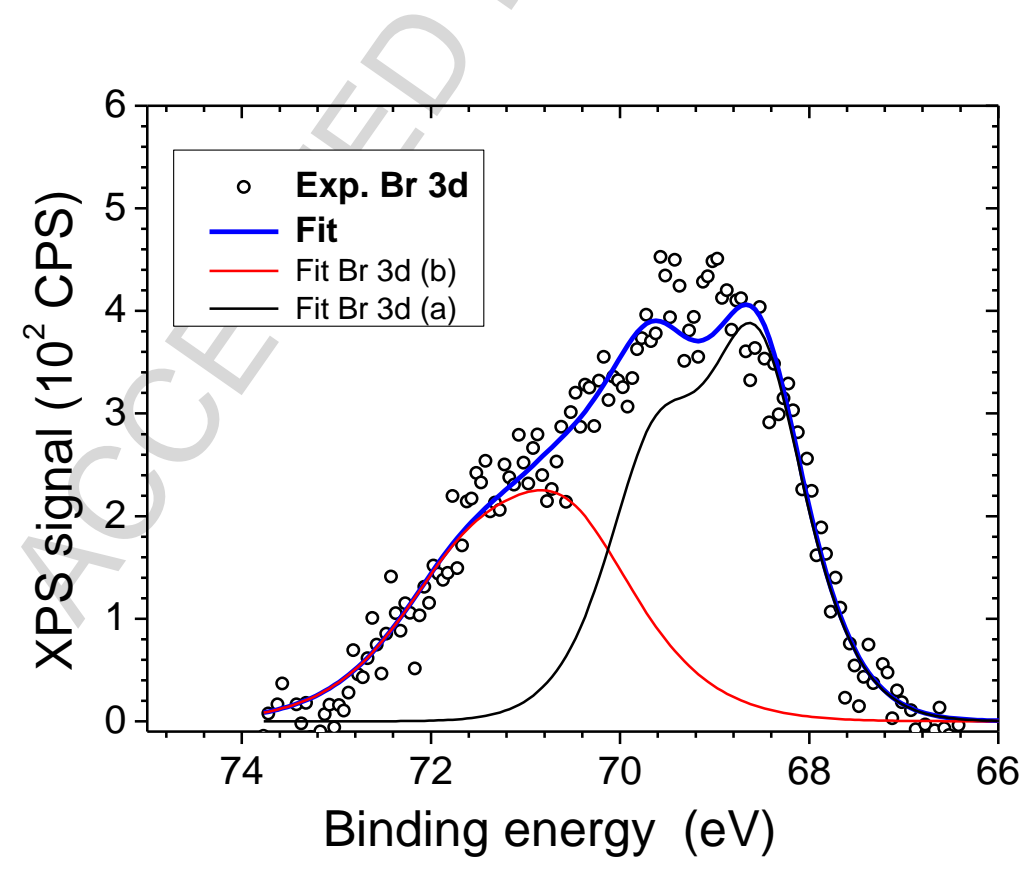

Fig. 5. XPS data $\left(\alpha=45^{\circ}\right)$ after $\left[\mathrm{Mo}_{6} \mathrm{I}_{8}\right]^{4+}$ cluster immobilization showing the $\left(\mathrm{Br} 3 \mathrm{~d}_{3 / 2}, \mathrm{Br} 3 \mathrm{~d}_{5 / 2}\right)$ doublet. Besides the main peak (black line), a second component (red line) is observed at larger binding energy $(\Delta E=2.0 \mathrm{eV})$. 


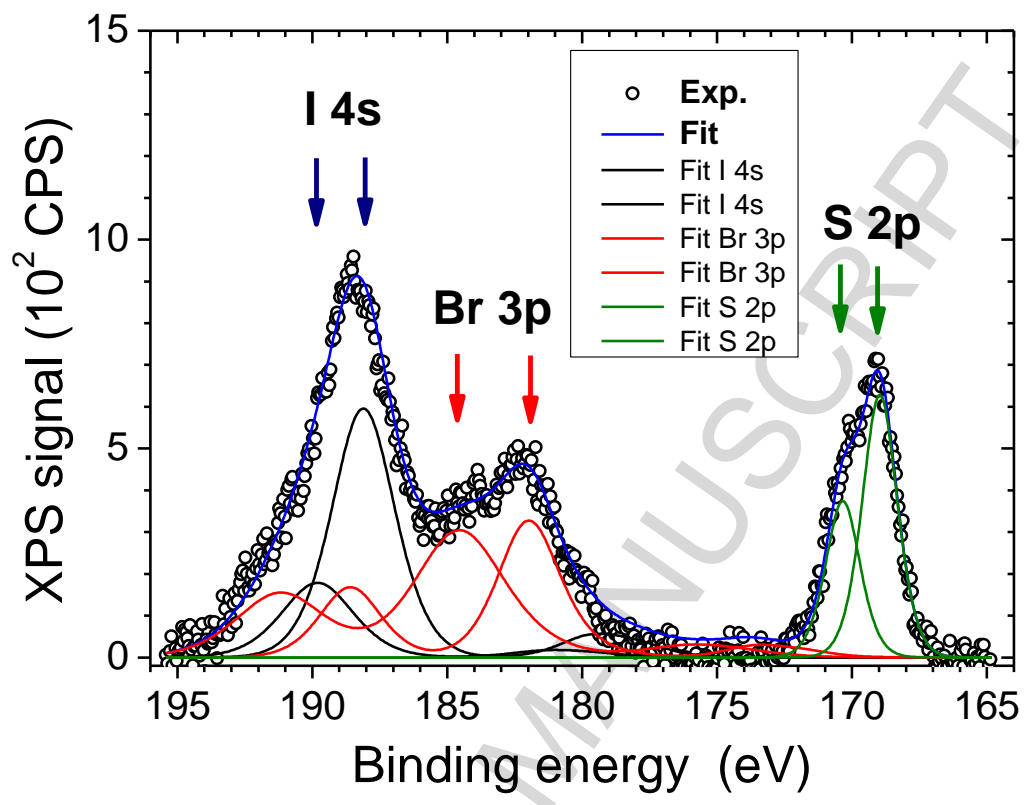

Fig. 6. XPS data $\left(\alpha=45^{\circ}\right)$ after $\left[\mathrm{Mo}_{6} \mathrm{I}_{8}\right]^{4+}$ cluster core immobilization with fitted peaks which include X-ray source satellites. A single component is observed with the sulfur ( $\mathrm{S} 2 \mathrm{p}_{1 / 2}, \mathrm{~S} 3 \mathrm{p}_{3 / 2}$ ) doublet (green), while the broad I $4 \mathrm{~s}$ (black) and $\mathrm{Br} 3 \mathrm{p}\left(3 \mathrm{p}_{1 / 2}, 3 \mathrm{p}_{3 / 2}\right)$ doublet (red) were fitted with two components.

Let us consider first the bromine labelling element core levels. Both the weaker $\left(\mathrm{Br} 3 \mathrm{~d}_{3 / 2}, \mathrm{Br}\right.$ $\left.3 \mathrm{~d}_{5 / 2}\right)$ doublet near $70 \mathrm{eV}$ (Fig. 5) and the stronger $\left(\mathrm{Br} 3 \mathrm{p}_{1 / 2}, \mathrm{Br} 3 \mathrm{p}_{3 / 2}\right)$ doublet near $183 \mathrm{eV}$ (Fig. 6) were used to estimate the average number of triflate anions which were not exchanged by surface pyridine $\left(\mathrm{Py}^{\mathrm{S}}\right)$. (i) The $\mathrm{Br} 3 \mathrm{~d}$ signal at $70 \mathrm{eV}$ being broader than expected from the doublet separation $(\approx 1 \mathrm{eV})$, data decomposition reveals the presence of two doublets separated by $\Delta E \approx 2.0 \mathrm{eV}$ with an intensity ratio of $\approx 0.6 \pm 0.1$. The ratio $(\mathrm{Br} 3 \mathrm{~d} / \mathrm{I} 4 \mathrm{~d})=0.17$ provides an average number of 1.5 bromopyridine units per bound metallic cluster. (ii) Decomposition of the 
Br 3p signal near $183 \mathrm{eV}$ also requires two $\left(\mathrm{Br} 3 \mathrm{p}_{1 / 2}, \mathrm{Br} 3 \mathrm{p}_{3 / 2}\right)$ doublets (Fig. 6) with a total intensity consistent with the $\mathrm{Br} 3 \mathrm{~d}$ fitting.

As far as the counter anions are concerned, the $\mathrm{C}$ 1s spectrum shows a high binding energy (292.7 eV) component (not shown) assigned to $\mathrm{CF}_{3}$ moieties pertaining to triflate anions $\left(\mathrm{CF}_{3} \mathrm{SO}_{3}{ }^{-}\right)$which remain on the surface after treatment with 3-bromopyridine. This result consistent with step III (Scheme 2) is confirmed by the presence of F 1s and S 2p signals at 684.2 $\mathrm{eV}$ and $169.0 \mathrm{eV}$, respectively. Figure 6 shows the $\left(\mathrm{S} 2 \mathrm{p}_{1 / 2}, \mathrm{~S} 2 \mathrm{p}_{3 / 2}\right)$ doublet with the expected spin orbit separation of $1.37 \mathrm{eV}$ and an intensity ratio of 0.58 . Its position is consistent with triflate moieties [45]. The peak area ratio (S 2p/I 4d) is 0.21 , which means that, on average, each bound metallic cluster is surrounded by 1.8 triflate units. This ratio is obtained with a good precision; however, this value might be underestimated because some triflate moieties may be lost during XPS measurements, as reported previously [35].

In summary, the $\mathrm{Br} 3 \mathrm{~d}$ intensity provides $(x-y)=1.5 \pm 0.3$ bromopyridine unit per bound metallic cluster and I $4 \mathrm{~d}$ decomposition gives $(6-x)=1 \pm 0.1$ apical iodine per cluster, on average. It can be concluded that each metallic cluster is bound to the organic monolayer surface through either three or four pyridine anchoring groups, corresponding respectively to $\left(\mathrm{CF}_{3} \mathrm{SO}_{3}\right)_{3}\left[\mathrm{Mo}_{6} \mathrm{I}_{8}^{\mathrm{i}} \mathrm{I}_{1}^{\mathrm{a}}\right.$ $\left.(\mathrm{Py})^{\mathrm{S}}{ }_{3}(\mathrm{Py}-\mathrm{Br})^{\mathrm{a}}{ }_{2}\right]$ and $\left(\mathrm{CF}_{3} \mathrm{SO}_{3}\right)_{3}\left[\mathrm{Mo}_{6} \mathrm{I}_{8}^{\mathrm{i}} \mathrm{I}_{1}^{\mathrm{a}}\left(\mathrm{Py}^{\mathrm{S}}\right)^{\mathrm{a}}{ }_{4}(\mathrm{Py}-\mathrm{Br})^{\mathrm{a}}{ }_{1}\right]$. Considering that one apical $\mathrm{I}^{\mathrm{a}}$ is attached to the cluster core, a (-3) charge must be carried by three triflate moieties in order to maintain the total charge balance.

\subsection{Electrical transport}

The $I-V$ characteristics were measured at room temperature on the bare $\mathrm{Hg} / / \mathrm{a}-\mathrm{C}-p \operatorname{Si}(111)$ junction, after grafting of the pyridine-terminated monolayer and further immobilization of $\left[\mathrm{Mo}_{6} \mathrm{I}_{8}\right]^{4+}$ cluster core monolayer. Current density $J(V)$ and numerically derived conductance 
$G(V)=(\mathrm{d} J / \mathrm{d} V)$ characteristics were reproducible at several points of the sample, measured over several days.
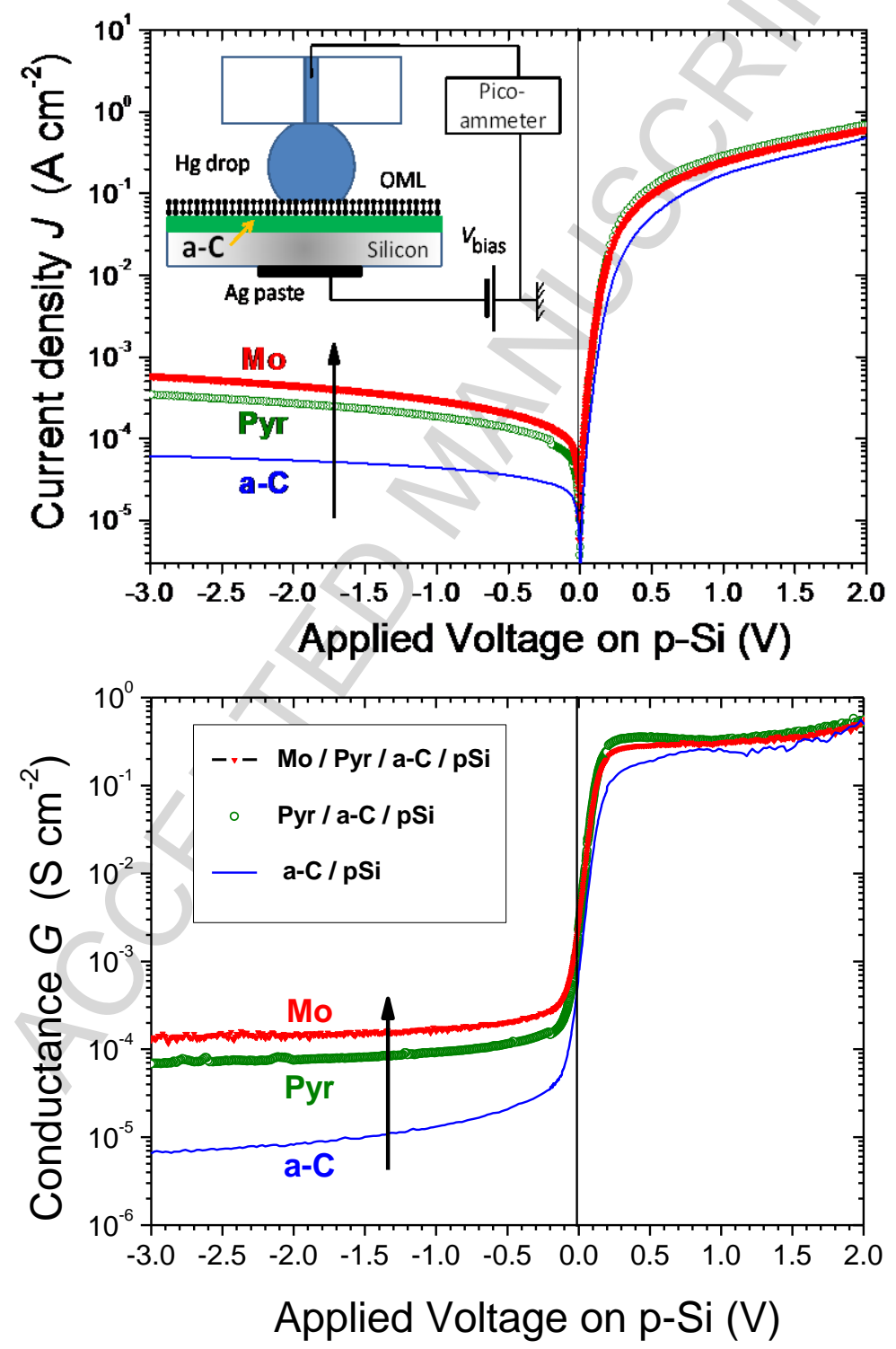

Fig. 7. Current density (a) and conductance (b) characteristics of $\mathrm{Hg} / /$ molecular layer / a-C / p-type Si junctions $(T=296 \mathrm{~K})$ : before (blue line) and after (green circles) grafting of a pyridineterminated alkyl monolayer to a-C ; after complexation of a monolayer of cluster cores (red triangles). 
Figure 7 shows strong rectification for all junctions with a rectification factor, $J(+2 \mathrm{~V}) / J(-$ $2 \mathrm{~V}$ ), exceeding four decades for the $\mathrm{Hg} / / \mathrm{a}-\mathrm{C}-p \operatorname{Si}(111)$ heterojunction. The saturation conductance value, observed at positive bias as expected for $p$-type Si substrates, corresponds to the bulk resistance of the Si substrate. After thermal grafting of the alkyl monolayer and pyridine functionalization, an increase in the reverse bias current by about one decade is observed.

In the forward bias regime, $I-V$ characteristics remain nearly unchanged after Mo cluster monolayer immobilization. The sharp exponential rise in the current density observed for increasing positive bias, corresponds to a decrease of the hole injection barrier from the $p$-type semiconductor into a-C. For the $\mathrm{Hg} / /$ pyridine - alkyl $-\mathrm{a}-\mathrm{C}-p$ Si junction, the low forward bias $(0-0.15 \mathrm{~V})$ range can be accurately fitted with a transport mechanism limited by a Schottky barrier, using an effective barrier $\Phi_{\mathrm{EFF}}=0.65 \mathrm{eV}$ and an ideality factor $n=1.23$.

In the reverse bias regime, the current density increases after thermal grafting of pyridineterminated alkyl monolayer, but no further effect can be detected after the cluster immobilization step. This regime corresponds to injection of minority carriers (electrons) from $p$-type $\mathrm{Si}$ and transport through the a-C film.

\section{Discussion}

A monolayer of octahedral $\left[\mathrm{Mo}_{6} \mathrm{I}_{8}\right]^{4+}$ cluster cores has been immobilized through complexation with a pyridine functionalized amorphous carbon surface. Each metallic cluster is bound to the organic monolayer surface through either three or four pyridine anchoring groups, 
corresponding respectively to $\left(\mathrm{CF}_{3} \mathrm{SO}_{3}\right)_{3}\left[\mathrm{Mo}_{6} \mathrm{I}_{8}^{\mathrm{i}} \mathrm{I}_{1}^{\mathrm{a}}{ }_{1}\left(\mathrm{Py}^{\mathrm{S}}\right)_{3}^{\mathrm{a}}{ }_{3}(\mathrm{Py}-\mathrm{Br})_{2}^{\mathrm{a}}{ }_{2}\right]$ and $\left(\mathrm{CF}_{3} \mathrm{SO}_{3}\right)_{3}\left[\mathrm{Mo}_{6} \mathrm{I}_{8}^{\mathrm{i}} \mathrm{I}_{1}^{\mathrm{a}}\right.$ $\left.(\mathrm{Py})^{\mathrm{S}}{ }_{4}^{\mathrm{a}}(\mathrm{Py}-\mathrm{Br})_{1}^{\mathrm{a}}\right]$, where three triflate moieties are required to maintain the total charge balance.

This work shows that $\left[\mathrm{Mo}_{6} \mathrm{I}_{8}\right]^{4+}$ cluster cores are strongly bound to the pyridine functionalized carbon surface through multiple pyridine anchoring sites. Conversely, it might also indicate that clusters with fewer binding sites (being less stable) have been untied from the surface during the grafting process and that the complexation reaction is thus partly reversible. On the other hand, it cannot be excluded that the less stable cluster core configurations, e.g. with a low number of anchoring sites, have been removed during step III of the process.

A large fraction (more than 60\%) of available pyridine sites at the functionalized carbon surface $\left(\Sigma_{\mathrm{PYR}}=2.9 \times 10^{13} \mathrm{~cm}^{-2}\right)$ are participating in cluster complexation, as derived from the average number of anchoring sites per cluster $\left(N_{\mathrm{PYR}}=3.5 \pm 0.4\right)$. Considering the topological constraints related to the octahedral cluster geometry, cluster attachment to the alkyl monolayer surface through 3 or 4 pyridine anchoring sites indicates that the pyridine-terminated alkyl chains are flexible enough to accommodate up to four bonds. This work confirms previous results for $\mathrm{Mo}_{6}$ clusters immobilization on $\mathrm{Si}(111)$ where the number of anchoring groups was closer to 4 [35].

From crystallographic data, the footprint of the $\left[\mathrm{Mo}_{6} \mathrm{I}_{8}\right]^{4+}$ cluster core with bromopyridine complexation can be estimated at $2.2 \mathrm{~nm}^{2}$, i.e. the densely packed monolayer ideally represents $4.5 \times 10^{13}$ clusters $/ \mathrm{cm}^{2}$. Experimentally, the $\mathrm{Mo}_{6} \mathrm{I}_{8}-$ pyridine - alkyl $-\mathrm{a}-\mathrm{C}$ system shows a moderately large density of clusters $\left(\Sigma_{\text {Mo6l8 }}=9.2 \times 10^{12} \mathrm{~cm}^{-2}\right)$ providing a specific area of $A_{\text {mol }}=$ $10.9 \mathrm{~nm}^{2}$ per bound cluster.

The binding energy of the main (Mo $3 \mathrm{~d}_{3 / 2}$, Mo $3 \mathrm{~d}_{5 / 2}$ ) doublet is identical to that observed for the starting product $\left[\left(n-\mathrm{C}_{4} \mathrm{H}_{9}\right)_{4} \mathrm{~N}\right)_{2} \mathrm{Mo}_{6} \mathrm{I}_{14}$, being thus consistent with the expected oxidation 
number of +II. However, a fraction of the photoelectrons emitted by Mo atoms have a smaller kinetic energy $(\Delta E \approx 2.75 \mathrm{eV})$ with an intensity ratio $\left(\mathrm{Mo}^{*} / \mathrm{Mo}^{\mathrm{II}}\right)=0.23 \pm 0.05$. A similar effect could be detected after grafting of $\left[\mathrm{Mo}_{6} \mathrm{I}_{8}\right]^{4+}$ cluster cores on pyridine-functionalized Si(111), however with an extremely weak intensity of the Mo* peak [35]. Note that two different environments are found in the $\mathrm{Mo}_{6} \mathrm{I}_{8}$ - pyridine - alkyl - a-C assembly with either one or two (Py-Br) unit(s) at apical positions, while a single (Py-Br) is essentially obtained in the $\mathrm{Mo}_{6} \mathrm{I}_{8}-$ pyridine - alkyl - Si assembly. Two tentative explanations can be proposed:

(i) complexation by one or two bromopyridine group(s) possibly induces different local charge values on each cluster element, with a larger binding energy (apparent cluster core oxidation) arising from a larger number of electron withdrawing (Py-Br) units; however, a single peak being found in the $3 \mathrm{~d}$ and $4 \mathrm{~d}$ spectra of inner iodine atoms, the hypothesis of a global charging of the cluster core seems unlikely.

(ii) in XPS studies of transition metal complexes, additional structures at higher apparent binding energy have been reported and attributed to charge transfer between the ligand and the central atom upon creation of a core hole [46]. In the case of octahedral $\left[\mathrm{Mo}_{6} \mathrm{X}_{8}\right]^{4+}$ cluster cores, although such effect has not been reported, different number of $(\mathrm{Py}-\mathrm{Br})$ and $\left(\mathrm{Py}^{\mathrm{S}}\right)$ complexation groups could induce different charge transfer mechanisms in the final electronic state after the photo-hole generation.

Electrical transport measurements performed with $\mathrm{Hg} / / \mathrm{Mo}_{6} \mathrm{I}_{8} /$ pyridine - alkyl / a-C / pSi(111) junctions show rectifying current-voltage characteristics, nearly independent of the pyridine functionalization or $\left[\mathrm{Mo}_{6} \mathrm{I}_{8}\right]^{4+}$ cluster core immobilization. However, they do not reveal any signature of the $\left[\mathrm{Mo}_{6} \mathrm{I}_{8}\right]^{4+}$ cluster core immobilization, in contrast with the $\mathrm{Hg} / / \mathrm{Mo}_{6} \mathrm{I}_{8}-$ pyridine - alkyl - p Si junctions investigated previously. This indicates that band bending 
induced by the $\left[\mathrm{Mo}_{6} \mathrm{I}_{8}\right]^{4+}$ cluster core monolayer is allowed by the low density of states at the OML - Si interface, while it is forbidden by the high density of localized $\left(\pi\right.$ and $\left.\pi^{*}\right)$ states in amorphous carbon $[1,47,48]$. The increase in reverse bias current after thermal grafting of the $\omega$ functionalized monolayer at $160^{\circ} \mathrm{C}$, observed in Fig. 7, may be attributed to an increase in the hopping conductivity of a-C as a result of partial $\mathrm{sp}^{3}$-to-sp ${ }^{2} \mathrm{C}$ conversion (larger density of localized $\pi$ states) [48].

\section{Conclusions}

Molecular junctions incorporating electroactive $\left(\mathrm{Mo}_{6} \mathrm{I}_{8}^{\mathrm{i}} \mathrm{X}_{6}^{\mathrm{a}}\right)$ transition metal cluster units have been obtained by covalent grafting of a pyridine-terminated alkyl monolayer and subsequent pyridine complexation at apical cluster positions of the clusters. The very smooth surface of tetrahedral a-C films grown by pulsed laser deposition allows quantitative XPS determination of the cluster packing density $\left(\Sigma_{\mathrm{OML}}=9.2 \times 10^{12} \mathrm{~cm}^{-2}\right)$ and the corresponding specific area $A_{\text {mol }}=$ $10.9 \mathrm{~nm}^{2}$ per bound cluster.

Considering topological constraints due to the octahedral geometry, cluster attachment to the surface through 3 or 4 pyridine anchoring sites indicates that the pyridine-terminated alkyl chains are flexible enough to accommodate up to four bonds, providing robust surface immobilization. The pyridine complexation strategy with multiple anchoring sites on the surface of this functional architecture may thus be interesting for potential applications of octahedral clusters in photochemistry and catalysis, including different carbon materials (amorphous carbon, glassy carbon, pyrolyzed photoresist films, graphene ...). 


\section{Acknowledgement}

This work was supported by Agence Nationale de la Recherche (ANR-07-BLAN-0170-02, project "CLUSTSURF”). 


\section{References}

[1] Robertson J. Diamond-like amorphous carbon. Mat Sci Eng 2002;R37:129-281.

[2] Donnet C, Erdemir A. Tribology of diamond like carbon films: fundamentals and applications. New York, Springer, 2008.

[3] Lmimouni K, Legrand C, Dufour C, Chapoton A, Belouet C. Diamond-like carbon films as electron-injection layer in organic light emitting diodes. Appl Phys Lett 2001;78:2437-9.

[4] Cachet H, Deslouis C, Chouiki M, Saidani B, Conway NMJ, Godet C. Electrochemistry of nitrogen-incorporated amorphous carbon films. J Electrochem Soc 2002;149:E233-41.

[5] McCreery RL. Advanced carbon electrode materials for molecular electrochemistry. Chem Rev 2008;108:2646-87.

[6] Khadro B, Sikora A, Loir AS, Errachid A, Garrélie F, Donnet C, et al. Electrochemical performances of B doped and undoped diamond-like carbon (DLC) films deposited by femtosecond pulsed laser ablation for heavy metal detection using square wave anodic stripping voltammetric (SWASV) technique. Sensors and Actuators B: Chemical, 2011;155:120-5.

[7] Sun B, Colavita PE, Kim H, Lockett M, Marcus MS, Smith LM, et al. Covalent photochemical functionalization of amorphous carbon thin films for integrated real-time biosensing. Langmuir 2006;22:9598-605.

[8] Angione MD, Pilolli R, Cotrone S, Magliulo M, Mallardi A, Palazzo G, et al. Carbon based materials for electronic bio-sensing. Materials Today 2011;14:424-33.

[9] Pinson J, Podvorica F. Attachment of organic layers to conductive or semiconductive surfaces by reduction of diazonium salts. Chem Soc Rev 2005;34:429-39.

[10] Szunerits S, Boukherroub R. Different strategies for functionalization of diamond surfaces. J Solid State Electrochem 2008;12:1205-18.

[11] Ababou-Girard S, Solal F, Fabre B, Alibart F, Godet C. Covalent grafting of organic molecular chains on amorphous carbon surfaces. J Non-Cryst Solids;2006:2011-2014.

[12] McCreery RL, Bergren AJ. Progress with molecular electronic junctions: meeting experimental challenges in design and fabrication. Advanced Materials 2009;21:4303-22. 
[13] Yesildag A, Ekinci D. Covalent attachment of pyridine-type molecules to glassy carbon surfaces by electrochemical reduction of in situ generated diazonium salts. Formation of ruthenium complexes on ligand-modified surfaces. Electrochimica Acta 2010;55:7000-9.

[14] Moreno-Castilla C, Maldonadao-Hódar FJ. Carbon aerogels for catalysis applications: An overview. Carbon 2005;43:455-65.

[15] Zaman S, Smith KJ. A review of molybdenum catalysts for synthesis gas conversion to alcohols: catalysts, mechanisms and kinetics. Catalysis Reviews: Science and Engineering 2012;54:41-132.

[16] Braunstein P, Oro LA, Raithby PR. Metal clusters in chemistry, Vol. I and II, Wiley: Weinheim, 1999.

[17] Cordier S, Dorson F, Grasset F, Molard Y, Fabre B, Haneda H, Sasaki T, Mortier M, Ababou-Girard S, Perrin C. Journal of Cluster Science 2009; 20, 9-21.

[18] Cordier S, Molard Y, Brylev K, Mironov Y, Grasset F, Fabre B, et al. Advances in the Engineering of Near Infrared Emitting Liquid Crystals and Copolymers, Extended Porous Frameworks, Theranostic Tools and Molecular Junctions Using Tailored $\operatorname{Re}_{6}$ Cluster Building Blocks. J Clust Sci 2015 [10.1007/s10876-014-0734-0].

[19] Hughbanks T, Hoffman R. Molybdenum chalcogenides: Clusters, chains, and extended solids. The approach to bonding in three dimensions. J Am Chem Soc 1983;105:1150-62.

[20] Maverick AW, Nadjdzionek JS, MacKenzie D, Nocera DG, Gray HB. Spectroscopic, electrochemical, and photochemical properties of molybdenum (II) and tungsten (II) halide clusters. J Am Chem Soc 1983;105:1878-82.

[21] Johnston DH, Stern CL, Shriver DF. Synthesis of 12-metal clusters based on the $\left(\left[\mathrm{Mo}_{6} \mathrm{Cl}_{8}\right]^{4+}\right)$ core. X-ray structure of $(\mathrm{PPN})_{2}\left[\mathrm{Mo}_{6} \mathrm{Cl}_{8}^{\mathrm{i}}\left\{(\mu-\mathrm{NC}) \mathrm{Mn}(\mathrm{CO})_{2} \mathrm{Cp}\right\}_{6}^{\mathrm{a}}\right]$. Inorg Chem 1993;32:5170-5.

[22] Golden JH, Deng H, DiSalvo FJ, Fréchet JM, Thompson PM. Monodisperse metal clusters 10 Angstroms in diameter in a polymeric host: the 'monomer as solvent' approach. Science 1995;268:1463-6. 
[23] Mery D, Plault L, Ornelas C, Ruiz J, Nlate S, Astruc D, et al. From simple monopyridine clusters $\left[\mathrm{Mo}_{6} \mathrm{Br}_{13}(\mathrm{Py}-\mathrm{R})\right]\left[n-\mathrm{Bu}_{4} \mathrm{~N}\right]$ and hexapyridine clusters $\left[\mathrm{Mo}_{6} \mathrm{X}_{8}(\mathrm{Py}-\mathrm{R})_{6}\right]\left[\mathrm{OSO}_{2} \mathrm{CF}_{3}\right]_{4}$ ( $\mathrm{X}=\mathrm{Br}$ or $\mathrm{I})$ to cluster-cored organometallic stars, dendrons, and dendrimers. Inorg Chem 2006;45:1156-67.

[24] Kirakci K, Hosoda H, Cordier S, Perrin C, Saito G. A hybrid material based on $\left[\mathrm{Mo}_{6} \mathrm{Br}_{14}\right]^{2-}$

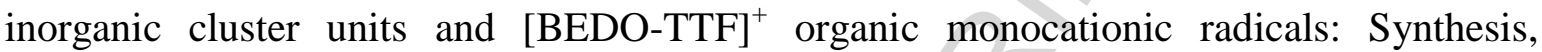
structure and properties of $(\mathrm{BEDO}-\mathrm{TTF})_{2} \mathrm{Mo}_{6} \mathrm{Br}_{14}(\mathrm{PhCN})_{4}$. J Solid State Chem 2006;179:3628-3635.

[25] Amela-Cortes M, Cordier S, Naumov N, Meriadec C, Artzner F, Molard Y. Hexacyano octahedral metallic clusters as versatile building blocks in the design of extended polymeric framework and clustomesogens. J. Mater. Chem. C 2014;2:9813-9823.

[26] Cordier S, Grasset F, Molard Y, Amela-Cortes M, Boukherroub R, Ravaine S, et al. Inorganic Molybdenum Octahedral Nanosized Cluster Units, Versatile Functional Building Block for Nanoarchitectonics. J Inorg Organomet Polym 2014:1-16.

DOI : 10.1007/s10904-014-0112-2

[27] Garreau A, Massuyeau F, Cordier S, Molard Y, Gautron E, Bertoncini P, et al. Color control in coaxial two-luminophore nanowires. ACS Nano 2013;7:2977-2987.

[28] Molard Y, Labbe C, Cardin J, Cordier S. Sensitization of $\mathrm{Er}^{3+}$ Infrared Photoluminescence Embedded in a Hybrid Organic-Inorganic Copolymer containing Octahedral Molybdenum Clusters. Adv Funct Mater 2013;23:4821-4825.

[29] Kamiguchi S, Nagashima S, Chihara T. Characterization of Catalytically Active Octahedral Metal Halide Cluster Complexes. Metals 2014;4:84-107.

[30] Barras A, Cordier S, Boukherroub R. Fast photocatalytic degradation of rhodamine B over $\left[\mathrm{Mo}_{6} \mathrm{Br}_{8}\left(\mathrm{~N}_{3}\right)_{6}\right]^{2-}$ cluster units under sun light irradiation. Appl Catal B 2012;123:1-8.

[31] Kumar P, Kumar S, Cordier S, Paofai S, Boukherroub R, Jain SL. Photoreduction of $\mathrm{CO}_{2}$ to methanol with hexanuclear molybdenum $\left[\mathrm{Mo}_{6} \mathrm{Br}_{14}\right]^{2-}$ cluster units under visible light irradiation. RSC Advances 4 (2014) 10420-10423. 
[32] Kumar S, Khatri OP, Cordier S, Boukherroub R, Jain SL. Graphene oxide supported molybdenum cluster: first heterogenized homogeneous catalyst for the synthesis of dimethylcarbonate from $\mathrm{CO}_{2}$ and methanol. Chemistry - A European Journal 21 (2015) 3488-3494.

[33] Barras A, Das MR, Devarapalli RR, Shelke MV, Cordier S, Szunerits S, et al. One-pot synthesis of gold nanoparticle/molybdenum cluster/graphene oxide nanocomposite and its photocatalytic activity. Appl Catal B 2013;130:270-276.

[34] Ababou-Girard S, Cordier S, Fabre B, Molard Y, Perrin C. Assembly of Hexamolybdenum Metallic Clusters on Silicon Surfaces. ChemPhysChem 2007;8:2086-2090.

[35] Fabre B, Cordier S, Molard Y, Perrin C, Ababou-Girard S, Godet C. Electrochemical and charge transport behavior of molybdenum-based metallic cluster layers immobilized on modified $n$ - and $p$-Type Si(111) surfaces. J Phys Chem C 2009;113:17437-46.

[36] Sabbah H, Ababou-Girard S, Zebda A, Fabre B, Deputier S, Perrin A, et al. Thermal grafting of organic monolayers on amorphous carbon and silicon (111) surfaces: a comparative study. Diamond Relat Mater 2009;18:1074-80.

[37] Zebda A, Sabbah H, Ababou-Girard S, Solal F, Godet C. Surface energy and photoelectron spectroscopy studies of amorphous carbon surfaces. Appl Surf Sci 2008;254:4980-91.

[38] Godet C, Sabbah H, Herve M, Ababou-Girard S, Deputier S, Perrin A, et al. Thermal stability of perfluorinated molecular monolayers immobilized on PLD amorphous carbon surfaces. Mater Sci Eng 2010;16:012003.

[39] Ababou-Girard S, Sabbah H, Fabre B, Zellama K, Solal F, Godet C. Organic monolayer grafting on amorphous carbon : surface preparation and packing density. J Phys Chem C 2007;111:3099-108.

[40] Strother T, Cai W, Zhao X, Hamers RJ, Smith LM. Synthesis and characterization of DNAmodified silicon (111) surfaces. J Am Chem Soc 2000;122:1205-9.

[41] Johnston DH, Gaswick DC, Lonergan MC, Stern CL, Shriver DF. Preparation of bis(tetrabutylammonium) octa( $\mu 3$-chloro)hexakis(trifluoromethanesulfonato)-octahedrohexamolybdate(2-), $\left(\mathrm{Bu}_{4} \mathrm{~N}\right)_{2}\left[\mathrm{Mo}_{6} \mathrm{Cl}_{8}^{\mathrm{i}}\left(\mathrm{CF}_{3} \mathrm{SO}_{3}\right)_{6}^{\mathrm{a}}\right]$ : a versatile starting material for 
substituted molybdenum(II) clusters containing the $\left[\mathrm{Mo}_{6} \mathrm{Cl}_{8}^{\mathrm{i}}\right]^{4+}$ core. Inorg Chem 1992;31:1869-73.

[42] Tanuma S, Powell CJ, Penn DR. Calculations of electron inelastic mean free paths. VIII. Data for 15 elemental solids over the 50-2000 eV range. Surf Interf Anal 2004;36:1-14.

[43] Katsuno T, Godet C, Orlianges JC, Loir AS, Garrelie F, Catherinot A. Optical properties of high-density amorphous carbon films grown by nanosecond and femtosecond pulsed laser ablation. Appl Phys A 2005;81:471-6.

[44] Godet C, David D, Sabbah H, Ababou-Girard S, Solal F. Bulk and surface plasmon excitations in amorphous carbon films measured by core-level loss spectroscopy. Appl Surf Sci 2009;265:6598-606.

[45] Lindberg BJ, Hamrin K, Johansson G, Gelius U, Fahlman A, Nordling C, et al. Molecular Spectroscopy by Means of ESCA II. Sulfur compounds. Correlation of electron binding energy with structure. Phys Scr 1970;1:286-98.

[46] Bagus P, Ilton E, Nelin C. Review: The interpretation of XPS spectra: Insights into materials properties. Surf Sci Reports 2013;68:68273-304.

[47] Arena C, Kleinsorge B, Robertson J, Milne WI, Welland ME. Electronic properties of tetrahedral amorphous carbon investigated by scanning tunneling microscopy. J Appl Phys 1999;85:1609-15.

[48] Godet C, Physics of bandtail transport in disordered carbons. Diamond Relat Mater 2003;12:159-65. 


\section{Prime Novelty Statement}

This work elucidates the binding mechanisms and determines the number of anchoring sites of octahedral metal clusters (potentially useful in photochemistry and catalysis) immobilized on tetrahedral a-C surfaces, using XPS characterizations. The pyridine complexation strategy $\left(\mathrm{Py}^{\mathrm{S}}-\mathrm{alkyl} / \mathrm{a}-\mathrm{C}\right)$ combines the robustness of the interface $\mathrm{C}-\mathrm{C}$ bonding and the multiplicity of anchoring sites on the functionalized surface. 


\section{Highlights}

1/ Transition metal clusters were grafted on amorphous carbon.

2/ Grafting using covalent bonding with a pyridine-terminated alkyl monolayer.

$3 /$ Very smooth surface of tetrahedral a-C films grown by pulsed laser deposition.

4/ Packing density and specific area per cluster were calculated by quantitative XPS 